\title{
Replacement of infected prosthesis on the ascending aorta with an abdominal aortic autograft in a young patient
}

\author{
Eugenio Neri, MD, Olivier Coffin, MD, Thomas Toscano, MD, PhD, Massimo Massetti, MD, Federico Bizzarri, MD, \\ Gianni Capannini, MD, Giacomo Frati, MD, and Carlo Sassi, MD, Siena, Italy
}

I nfection of a prosthesis on the ascending aorta is a serious complication associated with a high mortality. The standard approach to this problem includes excision and replacement or debridement and repair of infected thoracic aortic grafts. In most cases, extra-anatomic bypass and removal of the infected vascular graft are not possible and reconstruction of arterial continuity may be a difficult problem. We report the successful treatment of this life-threatening complication using a strategy in which an infected ascending aortic prosthesis was replaced by an abdominal aortic autograft. The technical aspects and the rationale of this approach are presented.

From the Istituto di Chirurgia Cardiovascolare Universita' agli Studi di Siena, Unita' Operativa di Chirurgia dell' Aorta Toracica, Siena, Italy.

Received for publication Dec 12, 2000; accepted for publication Dec 18, 2000.

Address for reprints: Eugenio Neri, MD, Istituto di Chirurgia Cardiovascolare Universita' agli Studi di Siena, Policlinico le Scotte, Viale M. Bracci, 53100 Siena, Italy (E-mail: euxneri@tin.it or nerie@unisi.it).

J Thorac Cardiovasc Surg 2001;122:194-5

Copyright $\odot 2001$ by The American Association for Thoracic Surgery

$0022-5223 / 2001 \$ 35.00+0 \quad \mathbf{1 2 / 5 4 / 1 1 3 7 4 6}$

doi:10.1067/mtc.2001.113746

\section{Case Presentation}

The patient was a 34-year-old man with diabetes who underwent urgent repair of a traumatic lesion of the ascending aorta consequent to an automobile accident. The ascending aorta, affected by a limited dissection, was replaced with a $24-\mathrm{mm}$ Dacron graft. The operation and the subsequent course were uneventful, with the exception of subxiphoid pericardial decompression on postoperative day 5. Six weeks after the operation, the patient was readmitted with fever $\left(40^{\circ} \mathrm{C}\right)$, chills, an abnormal white blood cell count $\left(32 \times 10^{9} / \mathrm{L}\right)$, an elevated erythrocyte sedimentation rate $(76 \mathrm{~mm}$ in the first hour), and blood cultures positive for methicillin-resistant Staphylococcus aureus. The antibiotic regimen included vancomycin, ofloxacin, ceftazidime, and gentamicin. Blood cultures became negative after 4 days, but intermittent fever persisted. Transesophageal echocardiography excluded valvular bacterial vegetation but revealed fluid accumulation around the prosthesis. Chest computed tomographic scan demonstrated a large perigraft abscess; therefore, the patient was taken to the operating room for treatment. Abdominal computed tomographic scan and duplex scan echography were obtained before the operation to exclude major structural abnormalities of the abdominal aorta.

The operation was performed in two steps to avoid contamination of the abdominal incision. The abdominal aorta was exposed through a retroperitoneal approach. Under moderate heparinization $(50 \mathrm{mg})$, the aorta was crossclamped below the renal arteries and 
above the iliac bifurcation, and the inferior mesenteric artery was divided for subsequent reimplantation. The abdominal aorta was then transected and harvested, dividing the lumbar arteries, whose ostia on the aortic side were sutured with single 5-0 polypropylene stitches. The aortic autograft was stored in sterile cold saline solution. It was free from structural abnormalities. Its diameter was 22 $\mathrm{mm}$ and its length was $55 \mathrm{~mm}$. The abdominal aorta was replaced by a cryopreserved abdominal aorta homograft and the inferior mesenteric artery was reimplanted. The patient was then repositioned in a supine decubitus position and the chest was opened through a redo sternotomy. We found a large perigraft abscess. Purulent fluid, which cultured positively for methicillin-resistant Staphylococcus aureus, had puddled around the aortic prosthesis and was in direct contact with the exposed suture lines.

After full heparinization left axillary artery and right atrial appendage were cannulated. The patient was cooled at $25^{\circ} \mathrm{C}$, the aorta crossclamped beyond the distal anastomosis of the graft, and retrograde blood cardioplegia administered.

After copious irrigation with povidone-iodine solution $(0.2 \%)$ and debridement of devitalized tissue, all synthetic material was removed. The ascending aorta was then replaced with the abdominal aorta autograft by means of 5-0 polypropylene continuous sutures. An irrigation device allowed intermittent irrigation of the pericardium with a solution composed of $0.03 \%$ of povidoneiodine with $1000 \mathrm{~mL}$ of physiologic saline solution 3 to 5 times a day. After each wash, the drainage tubes were clamped and the mediastinum filled with $0.5 \mathrm{~g}$ of vancomycin hydrochloride dissolved in $100 \mathrm{~mL}$ of physiologic saline solution and maintained for 30 minutes. The postoperative course was uncomplicated and the patient's temperature returned to normal limits over the next 6 days. The culture of drainage remained negative after 9 day of irrigation. The intravenous antibiotic regimen was continued for 15 days. The patient was discharged on postoperative day 30 , after demonstration by computed tomographic scan of normal healing of the abdominal aorta and no evidence of residual perigraft fluid or inflammation in the mediastinum. At 6 months he is free of symptoms with normal follow-up studies of the aorta. Both gallium 67 citrate and indium 111 labeled autologous leukocyte imaging reveal no evidence of residual sepsis.

\section{Discussion}

The reported incidence of graft infections of all types after thoracic aortic operations ranges from $0.9 \%$ to $1.9 \%,{ }^{1}$ and recent series of thoracic aortic graft infections reported an in-hospital mortality of $42 \% .^{2,3}$ The established principles regarding the management of an infected vascular prosthesis include explantation of the infected graft, extra-anatomic bypass of blood through a clean field, radical debridement of all infected/necrotic tissues, in situ irrigation with an antimicrobial solution, and systemic antibiotics. ${ }^{3}$ However, extra-anatomic bypass, the cornerstone of management for infected vascular grafts, is less realistic for infected thoracic aortic grafts because of anatomic and physiologic considerations. Instead, the standard surgical approach to this problem has been excision and in situ replacement of the infected prosthesis with another synthetic graft or a homograft.
Reconstruction with biomaterial has a lower infectability rate than that of prosthetic grafts, and experimental studies have shown that resistance to infection of fresh arterial allografts is close to that of autologous grafts. ${ }^{4}$

Nevertheless, freshly implanted homografts are exposed to immunologically mediated rejection, resulting in progressive degeneration of the elastic fibers and collagen connective tissue. Moreover, the infiltration of macrophages and Langerhans cells causes rarification of the tissue and necrosis ${ }^{5}$ that leads to a loss of the mechanical strength, aneurysm formation, and rupture. This sequence is not observed in cryopreserved arterial homografts, which undergo a limited cellular and humoral rejection. ${ }^{6}$ However, late degeneration and disruption of cryopreserved allografts has been documented ${ }^{7,8}$ and the risk of secondary rupture should be considered.

The strategy adopted in this patient relies on the virulence of the microbial agent, which imposed the choice of a substitute with the lowest infectability potential, and on the young age of the patient, which necessitated that we reduce as much as possible the risk of future reoperations on the ascending aorta.

Abdominal autograft is a fresh substitute, which fulfills the requisites of maximal resistance in a septic milieu and safety from the risks of rejection and late degeneration. The use of cryopreserved homograft in the abdominal position, although potentially at risk for late degeneration, was preferable to a prosthetic reconstruction in this patient. Moreover, prospective reoperations on this segment of the aorta carry lower operative risks than do reoperations on the thoracic aorta.

In addition to providing a novel technique for reconstruction of the ascending aorta, this case illustrates that control of infection is well achieved with abdominal aortic autograft. This method, however, requires further clinical evaluation and follow up.

\section{References}

1. Hargrove WC, Edmunds LH Jr. Management of infected thoracic aortic prosthetic grafts. Ann Thorac Surg. 1984;37:72-7.

2. Coselli JS, Koksoy C, LeMaire SA. Management of thoracic aortic graft infections. Ann Thorac Surg. 1999;67:1990-3.

3. Mathes DW, Yaremchuk MJ, Isselbacher EM, Madsen JC. Successful in situ treatment of an infected ascending aortic graft. Ann Thorac Surg. 2000;70:1410-2.

4. Moore WS, Swanson RJ, Campagna G, Bean B. The use of fresh tissue arterial substitutes in infected fields. J Surg Res. 1975;18:229-33.

5. Goffin Y, Grandmougin D, Van Hoeck B. Banking cryopreserved heart valves in Europe: assessment of a 5-year operation in an international tissue bank in Brussels. Eur J Cardiothorac Surg. 1996;10:505-12.

6. Vogt PR, Brunner-La Rocca HP, Carrel T, von Segesser LK, Ruef C, Debatin J, et al. Cryopreserved arterial allografts in the treatment of major vascular infection: a comparison with conventional surgical techniques. J Thorac Cardiovasc Surg. 1998;116:965-72.

7. Szilagyi DE, Rodriguez FT, Smith RF, Elliott JP. Late fate of arterial allografts: observations 6 to 15 years after implantation. Arch Surg. 1970;101:721-33.

8. Lehalle B, Geschier C, Fieve G, Stoltz JF. Early rupture and degeneration of cryopreserved arterial allografts. J Vasc Surg. 1997;25:751-2. 